\title{
Growth of Mercuric Iodide Crystals
}

\author{
J. C. Ugucioni*, M. Ferreira*, F. Fajardo ${ }^{\dagger}$, and M. Mulato* \\ * Departamento de Física e Matemática, Universidade de São Paulo, \\ Av. Bandeirantes, 3900, 14040-901, Ribeirão Preto, SP, Brazil \\ ${ }^{\dagger}$ Departamento de Física, Faculdad de Ciencias, Universidad Nacional de Colombia, Bogotá, Colômbia
}

Received on 4 April, 2005

\begin{abstract}
Mercuric Iodide $\left(\mathrm{HgI}_{2}\right)$ is a semiconductor candidate for the construction of $\mathrm{X}$ - and gamma-ray detectors for digital medical imaging due to its high atomic number $\left(\mathrm{Z}_{\mathrm{Hg}}=80, \mathrm{Z}_{I}=53\right)$. Also, $\mathrm{HgI}_{2}$ has a wide optical band-gap $(2.13 \mathrm{eV})$ and high photon absorption coefficient for high-energy radiation. Different structures can lead to varying electrical and optical properties of the final material. In this work, $\mathrm{HgI}_{2}$ crystals were produced by the solvent evaporation technique. The solvents used were ethanol (solubility around $20 \mathrm{mg} / \mathrm{ml} \mathrm{at} 25^{\circ} \mathrm{C}$ ), ether (solubility around $3.5 \mathrm{mg} / \mathrm{ml}$ at $25^{\circ} \mathrm{C}$ ) and acetone (solubility around $24 \mathrm{mg} / \mathrm{ml}$ at $25^{\circ} \mathrm{C}$ ). The evaporation conditions were varied in order to produce different final crystals. The Bérnard cells are responsible for crystallites formation due to the Bérnard-Maragoni convection in the liquid. Millimeter-sized crystals can be obtained as seen by Scanning Electron Microscopy.
\end{abstract}

Keywords: Growth; Mercuric Iodide $\left(\mathrm{HgI}_{2}\right)$; Solvent evaporation technique

\section{INTRODUCTION}

Many studies on high band gap semiconductor were published in the last decades, mainly for applications in X-and gamma- ray detectors [1-5]. The desired properties of the material are a high band gap (that leads to a low background current) and a high atomic number (that leads to high stopping power, and thus detection efficiency). In this context, the mercuric iodide $\left(\mathrm{HgI}_{2}\right)$ is one of these promising semiconductors. Its characteristics are high band gap around $2.13 \mathrm{eV}$ [5-7] and high atomic number [6-7].

Besides these characteristics, $\mathrm{HgI}_{2}$ can have 3 different solid phases: i) $\alpha-\mathrm{HgI}_{2}$ has a tetragonal structure and red color; ii) orange- $\mathrm{HgI}_{2}$ has also tetragonal structure, but with $\mathrm{Hg}$ atoms in different positions from the previous case and it is obviously orange; and iii) $\beta-\mathrm{HgI}_{2}$ has an orthorhombic structure and is yellow [3,8-9].

In this work, we investigated the cheap and easy crystal growth technique of solvent evaporation. For varying evaporation rates either a lateral film at the wall or millimeter-sized crystals at the bottom of the reservoir can be formed. This process is mainly dominated by the Bérnard-Maragoni convection in the liquid [10-12]. The crystals are investigated with Scanning Electron Microscopy (SEM).

\section{EXPERIMENTAL}

$\mathrm{HgI}_{2}$ films were previously obtained by physical vapor transport (PVT) and physical vapor deposition (PVD) [13-14]. In order to look for a cheaper fabrication process, we used the solvent evaporation technique, which was already used for crystals growth $[1,15]$.

The solution $(70 \mathrm{ml})$ must be prepared with a volatile solvent and $\mathrm{HgI}_{2}$ powder (99,9\% purity from Carlo Erba S.A.). The solution is placed inside a glass reservoir. The solvent is evaporated from the system, with varied and controlled rates. After the complete evaporation of the solvent, different struc- tures were found at the bottom and at the wall of the reservoir.

The solvents used in this study were ethanol, acetone (both with 99,5\% purity from LabSynth Ltda.) and ether (99.99\% purity from Chemco Ltda). Different concentrations of $\mathrm{HgI}_{2}$ can be obtained at saturation: $20 \mathrm{mg} / \mathrm{ml}$ in ethanol, $24 \mathrm{mg} / \mathrm{ml}$ in acetone and $3.5 \mathrm{mg} / \mathrm{ml}$ in ether $[16,17]$.

Four experimental conditions were used: the solution was placed inside the reservoir, which top was not covered, and the system was inserted inside an exhausting hood that operates at maximum exhaustion. This will be called high evaporation rate; the solution was placed inside the reservoir, which top was not covered, and the system was inserted inside an exhausting hood, which was turned off during the experiment. This will be called medium evaporation rate; the solution was placed inside the reservoir, which top was covered with filter paper, and the system was inserted inside an exhausting hood, which was turned off during the experiment. This will be called low evaporation rate; the solution was placed inside the reservoir, which top was covered with PVC-film, and the system was inserted inside an exhausting hood, which was turned off during the experiment. This will be called superlow evaporation rate.

The high-rate condition was used for ethanol and acetone, which rates were $\sim 10 \mathrm{ml} / \mathrm{h}$ for ethanol and $\sim 40 \mathrm{ml} / \mathrm{h}$ for acetone. The medium-rate condition was also used for the same solvents, leading to $\sim 0.5 \mathrm{ml} / \mathrm{ml}$ for ethanol and $\sim 1.4 \mathrm{ml} / \mathrm{h}$ for acetone. The low-rate condition was used also for the same solvents leading to $\sim 0.1 \mathrm{ml} / \mathrm{h}$ for ethanol and $\sim 1.2 \mathrm{ml} / \mathrm{h}$ for acetone. Finally, for the last condition of super-low-rate, we obtained the results of $\sim 0.01 \mathrm{ml} / \mathrm{h}$ for ethanol, $\sim 0.5 \mathrm{ml} / \mathrm{h}$ for acetone and $\sim 1.7 \mathrm{ml} / \mathrm{h}$ for ether. These results are summarized in table 1.

\section{RESULTS AND DISCUSSION}

Each experimental condition leads to a specific evaporation rate as seen in table 1. On top of that, each condition leads also 
TABLE I: Evaporation rates for several $\mathrm{HgI}_{2}+$ solvent saturated solutions under varying conditions of evaporation (see text).n.a. $=$ not available.

\begin{tabular}{|l|l|l|l|}
\hline $\begin{array}{l}\text { Evaporation } \\
\text { Condition }\end{array}$ & $\begin{array}{l}\text { Ethanol } \\
\mathbf{( m l} / \mathbf{h})\end{array}$ & $\begin{array}{l}\text { Acetone } \\
\mathbf{( m l} / \mathbf{h})\end{array}$ & $\begin{array}{l}\text { Ether } \\
\mathbf{( m l} / \mathbf{h})\end{array}$ \\
\hline High-rate & 10 & 40 & n.a. \\
\hline Medium-rate & 0.5 & 1.4 & n.a. \\
\hline Low-rate & 0.1 & 1.2 & n.a. \\
\hline Super Low-rate & 0.01 & 0.5 & 1.7 \\
\hline
\end{tabular}

to a final different rearrangement of the $\mathrm{HgI}_{2}$ material that is left behind (after the complete evaporation of the solvent), as can be seen at the left side of Fig. 1 .

The four solvent evaporation final conditions, using ethanol as solvent, are presented in Fig. 1. The same saturated solution was used for all the experiments. Fig. 1(a) corresponds to the high-rate condition. It can be observed that most of the $\mathrm{HgI}_{2}$ material evaporated together with the solvent. A small amount of material remains at the bottom and at the wall of the reservoir and the inner glass cylinder that was inserted to help the visualization of the process during evaporation. The measured temperature gradient from the center to the border of the surface of the solution was about $1^{\circ} \mathrm{C}\left(\mathrm{T}_{1}>\mathrm{T}_{2}\right)$. Fig. 1(b) corresponds to the medium-rate condition. Besides the same results as in Fig. 1(a), an additional well-defined thin ring can be seen at the walls. For the low-rate condition presented in Fig. 1(c), we observe that more material remains at the wall and at the bottom of the reservoir. In addition, the previously well-defined ring of Fig. 1(b) now becomes thicker, leading almost to a surface film. Finally, for the case of super lowrate, millimeter-sized crystals are formed at the bottom of the dish, and no film is formed at the wall of the reservoir or the inner cylinder. For the last three evaporation conditions the surface temperature gradient is smaller than $1^{\circ} \mathrm{C}$, but it could not be precisely measured with our experimental set-up. Further improvements are under way.

The results observed in Fig. 1 are the final consequence of the same effect: convections in the liquid. When confined in a reservoir, all liquids present a surface tension. In the case of this study, the surface tension depends on the position. Given the fact that the evaporation depends on the surface tension, then a surface with varying surface tension leads to an evaporation flux gradient, as illustrated in Fig. 2. This evaporation cools the surface and a temperature gradient is formed. This temperature gradient generates a line convection that is called Bérnard's cells [10-12]. The completed system is influenced by the Bérnard-Maragoni convection and the solute is carried to the wall, where it is fixed due to the electrostatic forces.

The final result of the process described above can be seen in Fig. 1(c). With increasing evaporation rate, the amount of material deposited at the wall of the reservoir should diminish, and that is indeed the case as seen in Fig. 1(b), where only a thin-ring remains. If the evaporation rate is further increased, to extremely large values, the Bérnard-Maragoni convection will have no influence at all on the transport of the solute. Note that the evaporation rate used in Fig. 1(a) is 20 times larger than in Fig. 1(b).

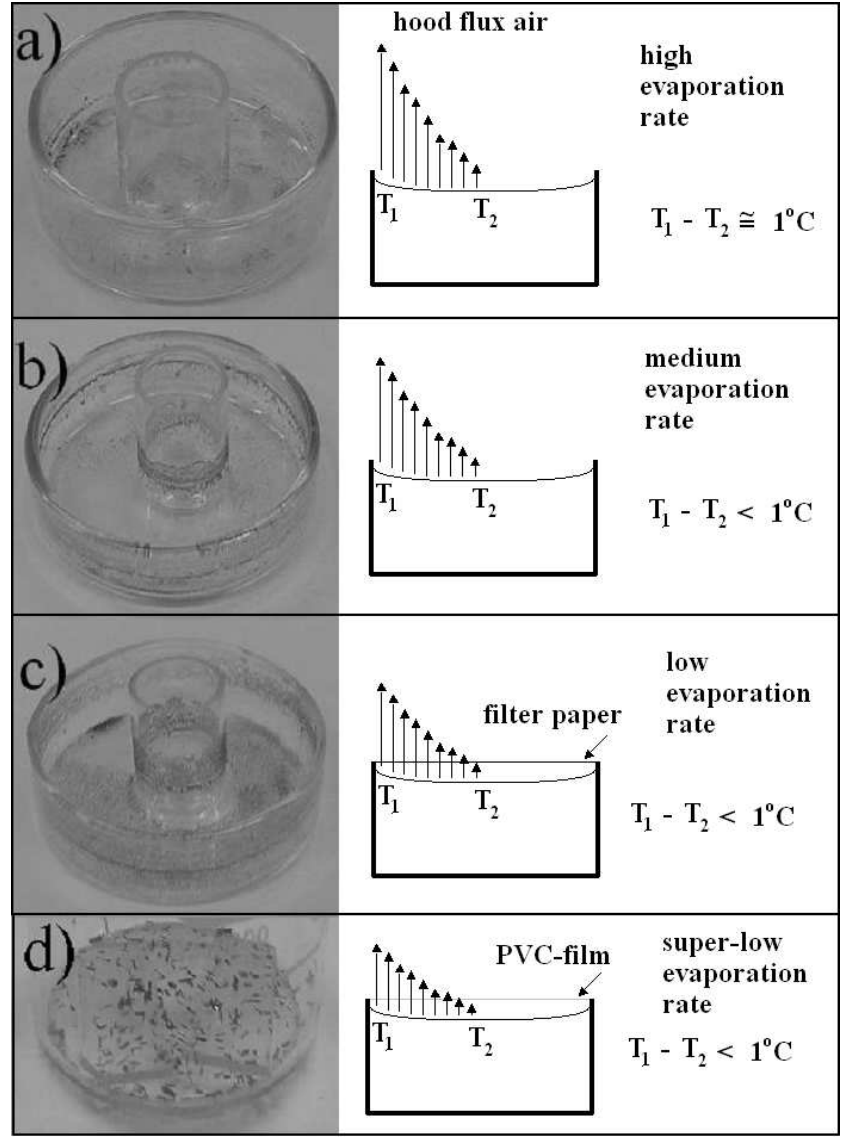

FIG. 1: Pictures of and solvent evaporation scheme from different evaporation conditions. The results correspond to ethanol as solvent: a) high-rate $(10 \mathrm{ml} / \mathrm{h}), \mathrm{b})$ medium-rate $0.5 \mathrm{ml} / \mathrm{h}), \mathrm{c})$ low-rate $(0.1$ $\mathrm{ml} / \mathrm{h})$ and d) super low-rate $(0.01 \mathrm{ml} / \mathrm{h})$. Note that a glass cylinder was inserted in the middle of the dish for additional visualization of the final result of the process of solvent evaporation.

At the other extreme of the experiment, if the temperature and surface tension gradients are both kept as small as possible, the transport of solute by the weak Bérnard-Maragoni convection will be even less important. As a final result, $\mathrm{HgI}_{2}$ will be able to nucleate crystal sites, and a crystal formation will take place, leading to large millimeter-sized rectangular crystals. These crystals are better seen in the SEM picture in Fig. 3(a).

Evidences of $\mathrm{HgI}_{2}$ crystal growth using the solvent evaporation technique were already reported in the past using ethyl alcohol [18] and acetone [8], but no definite explanation was presented for the phenomenon of crystal growth. Further numerical simulations should be developed based on our presented model. It should be kept in mind that the evaporation process depends on the total surface area of the liquid, and on the total starting volume, among other variables. For our experimental case, these two were always kept constant equal to about $20 \mathrm{~cm}^{2}$ and $80 \mathrm{ml}$.

Rectangular-shaped crystals, with a length of about $0.5 \mathrm{~mm}$ are seen in Fig. 3(a). The experiments were conducted under ambient light illumination. A small crystal size distribution 


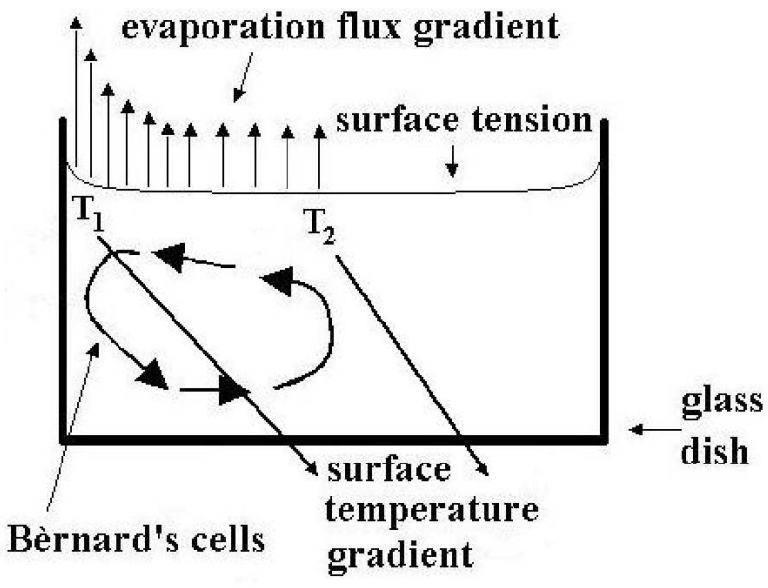

FIG. 2: Bérnard-Maragoni convection.

is observed. Some ramifications may have occurred due to localized instabilities of the Bérnard cells during the BérnardMaragoni convection. Finally, the process presented and discussed for the case of ethanol can also be extended for the other solvents (data not shown here due to the lack of space). Nevertheless, the appropriate evaporation rate should be tuned for each case.

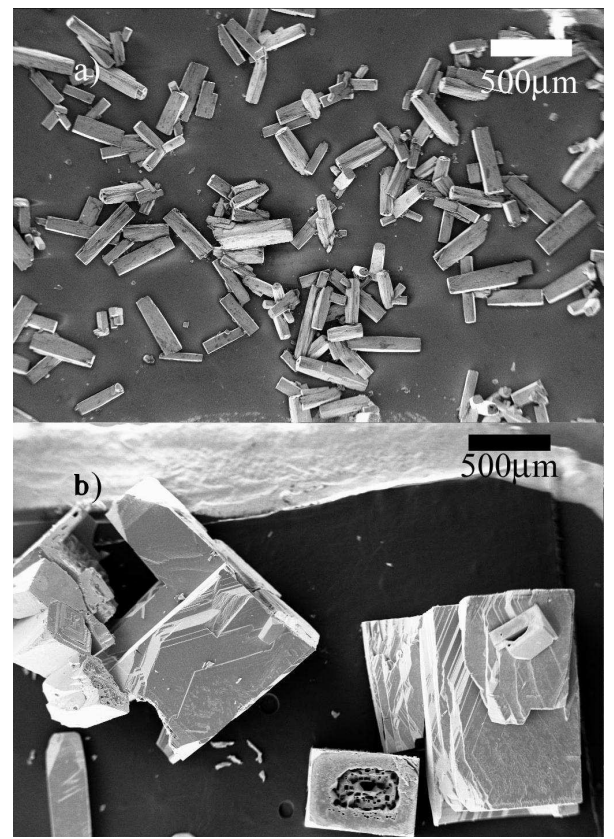

FIG. 3: SEM pictures for crystals grown using ethanol as solvent and the super low-rate condition: a) evaporation under normal ambient illumination and b) evaporation in the dark.

An additional experiment was conducted in order to investigate the possible influence of light during the crystal growth. The same experimental conditions adopted for the case of the data in Fig. 3(a) were reproduced in the dark. The resulting crystals are larger as can be observed in Fig. 3 (b). The rectangular aspect ratio is reduced and the crystals are as big as 1.5 mm. For some cases, as in the bottom center of Fig. 3(b), large craters can be observed from the top surface of the rectangle. This is not totally understood until the moment.

We also have no definite explanation for the fact that the crystals grown in the dark are larger than the crystals grown under illumination. Our guess is that during light exposure, high energy photons are absorbed by the $\mathrm{HgI}_{2}$ molecules. Somehow, crystal nucleation and growth is enhanced when the molecules are not excited. According to our knowledge, this effect has never been studied before for any semiconductor material. Further studies should deal with this subject with more details. For instance, as an alternative process, varying illumination conditions could be used together with thermal evaporation during the production of thin films.

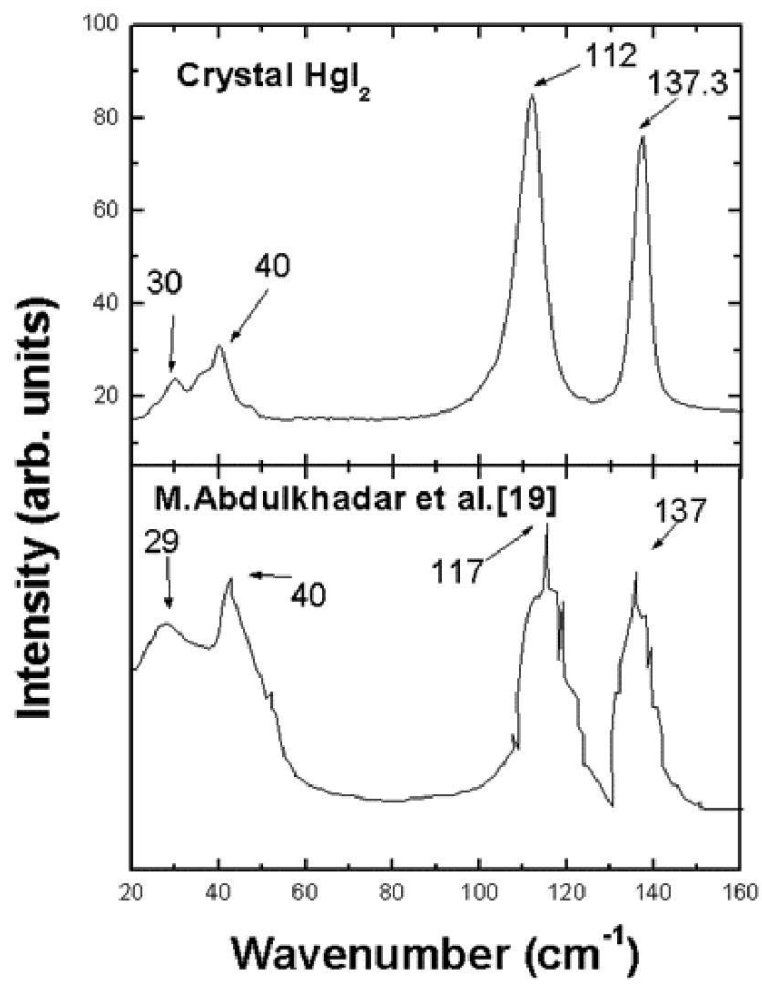

FIG. 4: Raman Scattering for the crystals from Fig. 3(b) at the top, compared to nanoparticles from M.Abdulkhadar [19].

The structural properties of the crystals shown in Fig. 3(b) were studied by Raman scattering spectroscopy. The results are shown at the top of Fig. 4. In this spectrum, the four Raman-shift peaks are identified at 30, 40112 and 137.3 $\mathrm{cm}^{-1}$. These results can be compared to the few data available in the literature. The bottom spectrum of Fig. 4 corresponds to $\mathrm{HgI}_{2}$ nanoparticles in air [19]. No appreciable difference can be seen, besides the fact that our spectrum is smoother, and there is only a peak shift difference at about $112 \mathrm{~cm}^{-1}$ that might be due to the size effect. No additional data are available in the literature. 


\section{CONCLUSION}

We investigated the solvent evaporation technique for the production of $\mathrm{HgI}_{2}$ crystals. A model for the evaporation process was proposed based on the formation of Bérnard cells during the Bérnard-Maragoni convection. For saturated solutions using ethanol as solvent, most of the solute evaporates with the solvent for evaporation rates of $10 \mathrm{ml} / \mathrm{h}$. With reduced evaporation rates, a well defined ring is formed on the wall of the dish. The process can be slowed with evaporation rates of about $0.01 \mathrm{ml} / \mathrm{h}$ leading to the formation of millimeter-sized crystals at the bottom of the reservoir, and no lateral film. The effect was also studied for acetone and ether as solvents, but the appropriate evaporation rate should be tuned for each case. Illumination during the evaporation process leads to smaller size crystals than in the dark, what indicates that crystal formation might be influenced by the excitation of $\mathrm{HgI}_{2}$ molecules. Further studies should focus on the structural and electrical properties of the obtained crystals, and a numerical simulation should be developed to confirm the proposed solvent-evaporation model.

\section{Acknowledgement}

This work was supported by CAPES, CNPq and FAPESP (01/08221-9) Brazilian agencies. We thank Prof. J. M. Rosolen and V. Lemos for experimental help.
[1] X. M. Wen, N. Ohno, J. Appl. Phys. 91(7), 4095 (2002).

[2] M. Zehangir Kabir, S. O. Kasap, Appl. Phys. Lett. 80(9), 1664 (2002).

[3] M. Hostettler, H. Birkedal, and D. Schwarzenbach, Helv. Chim. Acta 83, 1410 (2003).

[4] U. Khadilkar, R. Mamazza, C. S. Ferekides, D. L. Morel, R. DeVito, J. Sandoval, and L. van den Berg, Thin Solid Films 427, 381 (2003).

[5] F. Ayres, L. V. C. Assali, W. V. M. Machado, and J. F. Justo. Braz. J. Phys. 34, 681 (2004).

[6] M. Schieber, A. Zuck, S. Sanguinetti, M. Montalti, M. Braiman, L. Melekov, J. Nissenbaum, E. Grilli, M. Gruzzi, R. Tuchetta, W. Dulinski, D. Husson, and J. L. Riester, Nucl. Instr. Meth. Phys. Res. A428, 25 (1999).

[7] A. K. Solanki, A. Kashyap, T. Nautiyal, S. Auluck, and M. A. Khan, Phys. Rev.B 55(15), 9215 (1997).

[8] R. H. Bube, Phys. Rev. 106(4), 703 (1957).

[9] M. Hostettler, H. Birkedal, and D. Schwarzenbach, Acta Crystallog. B58, 903 (2002).

[10] C. Normand, Y. Pomeau, and M. G. Velarde, Rev. Modern Phys. 49(3), 581 (1977).
[11] R. F. Probstein, Physicochemical Hydrodynamics, JohnWiley \& Sons, cap. 10 (1994).

[12] T. Cuk, S. M. Troian, C. M. Hong, and S. Wagner. Appl. Phys. Lett. 77(13), 2063 (2000).

[13] R. Cadoret, J. Crys. Grow 146 (1995).

[14] M. Schieber, H. Hermon, A. Zuck, A. Vilensky, L. Melekhov, R. Shatunovsky, E. Meerson, Y. Saado, M. Lukach, E. Pinkhasy, S. E. Ready, and R. A. Street, J. Crys. Grow 225, 118 (2001)

[15] V. F. Agekyan, A. Yu. Serov, and Yu. A. Stepanov, Phys. Sol. State 42(10), 1832 (2000).

[16] J. C. Bailar Jr., H. J. Emeléus, Sir R. Nyholm, and A. F. Trotman-Dickenson, Comprehensive Inorganic Chemistry, Pergamon Press, 300 (1973).

[17] F. A. Cotton, G. Wilkinson, Advanced Inorganic Chemistry, $5^{a}$ ed., John Wiley \& Son, 611 (1989).

[18] F. C. Nix. Phys. Rev. 47, 72 (1935).

[19] M. Abdulkhadar, B. Thomas, Mat. Res. Bull. 30(10), 1301(1995). 